\title{
The Efficiency of Motorcycle Use in Illegal Bushmeat Transportation in Western Serengeti, Tanzania
}

\author{
Julius William Nyahongo ${ }^{1}$, Upendo Richard ${ }^{1} \&$ Eivin Røskaft ${ }^{2}$ \\ ${ }^{1}$ Department of Biology, University of Dodoma, P.O. Box 259, Dodoma, Tanzania \\ ${ }^{2}$ Department of Biology, Norwegian University of Science and Technology (NTNU), NO-7491 Trondheim, \\ Norway
}

Correspondence: Julius William Nyahongo, Department of Biology, University of Dodoma, P.O. Box 259, Dodoma, Tanzania. E-mail: nyahongo.jw@gmail.com; jnyahongo@udom.ac.tz

Received: February 15, 2021

Accepted: March 20, $2021 \quad$ Online Published: June 30, 2021

doi:10.5539/enrr.v11n1p18

URL: https://doi.org/10.5539/enrr.v11n1p18

\begin{abstract}
Bushmeat is an important source of protein, as well as economic income for communities in sub-Saharan Africa and Latin America. This study was conducted in north-western Serengeti, Tanzania, from July to September of 2019. Two villages were sampled for distance calculation: Kowak and Robanda. The snowballing technique was the sampling design adopted. Trained assistants identified at least one bushmeat vendor in each village to be interviewed, who was thereafter asked to identify another vendor known to him/her. The number of days spent delivering bushmeat packages to the illegal market (an average of $200 \mathrm{~km}$ ) from the bushmeat source was 16.8 days when using donkeys, 6.8 days when using bicycles, and 2.0 days when using motorcycles. Motorcycles were 8.4 and 3.4 times more efficient than donkeys and bicycles, respectively. Bicycles were 2.5 times more efficient than donkeys. The mean weights of bushmeat packages delivered by donkeys were $188.4 \mathrm{~kg}$ and $109.0 \mathrm{~kg}$ when using bicycles. Motorcycles delivered $185.0 \mathrm{~kg}$ of bushmeat per trip. The mean weights carried by donkeys and motorcycles were 1.7 times higher than those of bicycles. The mean depletion rates of motorcycles were $92.5 \mathrm{~kg}$ of bushmeat per day for a distance of $200 \mathrm{~km}$. Bicycles depleted $16.0 \mathrm{~kg}$, while donkeys only depleted $11.2 \mathrm{~kg}$ per day to the market. The use of motorcycles in bushmeat transportation increased the efficiency in delivering illegal bushmeat to predetermined illegal markets, and thus resulted in a high depletion rate. Wildlife authorities should introduce patrol systems that include the control of motorcycles close to protected areas. There should be day and night checkpoints in various places, such as large bridges that cannot be avoided and along rural pathways.
\end{abstract}

Keywords: People, Natural Resources Use, Food Security, Rural Development, Technology and Industrialisation

\section{Introduction}

Globally, protected areas play important roles in biodiversity conservation, and are cornerstones of sustainable development strategies (Cowlishaw \& Dunbar, 2000; Falconer, 1990; UNEP, 2008). Apart from their environmental benefits, these protected zones generate significant economic profits, as well as food resources, for the local communities that surround them (L Apaza et al., 2002). Bushmeat, which is derived from wild ungulates, is a critical source of meat protein that is consumed and traded among adjacent communities, as well as communities located far from protected areas (Campbell, Nelson, \& Loibooki, 2001; Mbete et al., 2011; D S Wilkie \& Carpenter, 1999). Wildlife provides up to 30 percent of the protein requirements of the rural population in Sub-Saharan Africa (Nasi et al., 2008). Elsewhere in Africa, consumers of bushmeat are price-sensitive, whereas commodities have a negative price elasticity of demand (Lilian Apaza et al., 2002; Fa, Juste, Burn, \& Broad, 2002; D. S. Wilkie \& Godoy, 2001). Further, bushmeat consumption tends to decrease with increasing prices, which explains why it is chosen by rural consumers when it is the cheapest meat in the marketplace (Rentsch \& Damon, 2013). Price elasticity also explains why urban consumers eat bushmeat as an occasional treat, as it is typically more expensive than substitutes (D. Wilkie et al., 2006).

In western Serengeti, Tanzania, bushmeat hunting is avital economic activity of adjacent communities that have largely been subsistence farmers since time immemorial (Mfunda \& Røskaft, 2010). The location of villages in the vicinity of protected areas influences the bushmeat consumption rate and prices, whereby consumption rates are higher in villages close to protected regions than in distant villages (Brashares, Golden, Weinbaum, Barrett, \& V, 2011; Ndibalema \& Songorwa, 2008; J. W. Nyahongo, Holmern, Kaltenborn, \& Røskaft, 2009).The low prices in 
villages adjacent to protected areas compared to distant villages might be due to the relatively large supply of illegal bushmeat and/or transportation and storage costs.

Illegal bushmeat operations usually take place inside protected zones (within $15 \mathrm{~km}$ of village boundaries) (Julius W Nyahongo, East, Mturi, \& Hofer, 2005). Hunters set traps (snare wires or pitfall traps) and wait for a victim that might fall in the trap after one or two days. Once the trap is successful, the hunters hire porters to assist in processing meat and to transport the carcasses to the village (personal experience). In the village, the meat is processed further and sundried in secretive locales to wait for buyers, who might be local consumers or distant bushmeat vendors that use different transportation systems (i.e. humans, donkeys, bicycles, motorcycles and occasionally vehicles) to ferry bags of bushmeat to illegally established markets (J. W. Nyahongo et al., 2009). The transportation systems that were primarily used in the past were donkeys and bicycles for long distances; however, within a village or between adjacent villages, human manpower was used. Processed bushmeat from inside the park largely involved the use of porters (people hired to carry the processed bushmeat carcasses). In such situations, at least 10 people were able to process and carry the carcass derived from one mature buffalo (Syncerus caffer) or giraffe (Giraffa camelopardalis) to the nearest village (Nyirocha Gaugeri, Personal Communication 2019). However, the introduction of cheap motorcycles from Asia swiftly replaced donkeys and bicycles (Sospeter Nyigoti, Personal Communication 2019).

Using motorcycles in bushmeat transportation increases the volume of bushmeat packages and the frequency of delivery at distant marketplaces, which might be in rural or urban places. This impacts bushmeat species, especially resident herbivores adjacent to villages. Migratory herbivores might also be affected, particularly during the dry season when they are close to villages in western and north-western Serengeti.

This study aims to evaluate the efficiency of motorcycles in the transportation of illegal bushmeat in western Serengeti compared to bicycles and donkeys. Specifically, we first compared the time (number of days) taken per trip by three transportation systems to deliver bushmeat packages to the marketplace. Second, we compared the weights of bushmeat packages delivered by each transportation system per trip.

\section{Study Areas}

This study was conducted in the north-western part of Serengeti National Park, Tanzania, from July to October of 2019. Sampling villages were systematically selected based on distance from the park's boundary lines, whereas the first village (Robanda) was located within $5 \mathrm{~km}$ of the park's boundaries, the second was located at least $45 \mathrm{~km}$ from the park's boundaries (the village of Rwamkoma), and the third sampling area was located in Rorya District ( $80 \mathrm{~km}$ from the park's boundaries). Here, several villages were sampled due to the low number of people dealing with bushmeat business in each village. The villages included were Kowak, Osiri, Ratia and Tatwe (Fig. 1). During the preliminary survey, only respondents from Robanda and Kowak agreed to participate, and were able to quantify the number of days taken to deliver the bushmeat to the marketplace and the weight of bushmeat packages carried per trip. This was probably because researchers have been working in the two villages for more than 20 years and have hence built long-term trust with villagers, including illegal bushmeat vendors. Hence, Robanda is hereafter regarded as a 'source village; an area where illegal hunting takes place', while Kowak is regarded as a 'sink or marketplace' located approximately $200 \mathrm{~km}$ from Robanda.

\section{The Greater Serengeti-Mara Ecosystem (GSME)}

The GSME is the ecosystem with the greatest concentration of large mammals in the world, ranging from grazers and browsers to carnivores (UNEP, 2008). The western part has become densely settled by a growing human population whose major economic activities are subsistence farming and livestock rearing. Agriculture is the chief source of income, but many people are attracted to the wildlife and the park's tourism employment opportunities, as well as the land for agriculture (UNEP, 2008). Illegal bushmeat hunting is widespread (Loibooki, Hofer, Campbell, \& Marion, 2002). Bushmeat is commonly sundried and used for home consumption or to generate income (Loibooki et al., 2002). 


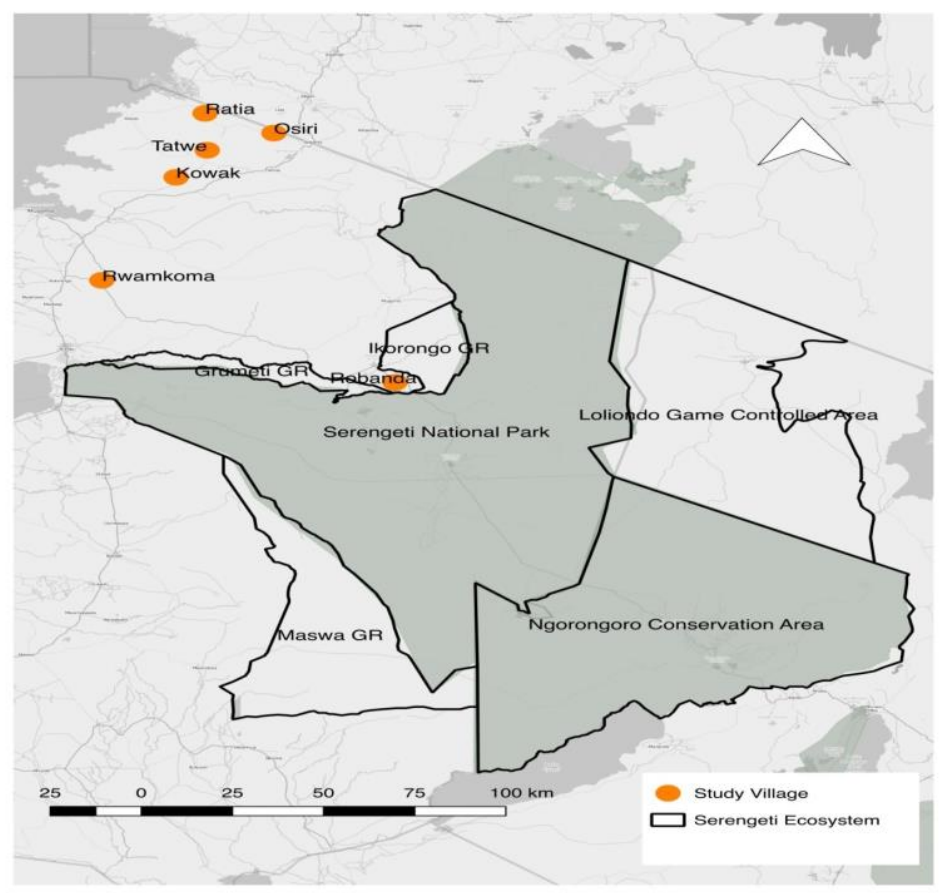

Figure 1. Map of the study location showing Serengeti National Park, Grumeti and Ikorongo Game Reserves, Lake Victoria and the surveyed villages

\section{Data Collection}

The sampling design adopted was a snowballing technique. In the two villages surveyed, one or more assistants were recruited. The assistants were trusted and respected people in the village. Some assistants were either bushmeat vendors themselves or those who have dealt with the bushmeat business in the past and have therefore acquired the experience to share information with researchers regarding transportation systems. Before being appointed to assist the project, he/she was asked to confirm whether he/she would like to participate in the exercise, and if he/she knew any illegal bushmeat hunters in the area. Once the first respondent was identified and agreed to be interviewed, we ensured them of confidentiality and that we were not interested in reporting who sells meat to the authorities; rather, we were interested in understanding the transportation systems and how such systems have changed over time due to the increased demand for bushmeat and the introduction of cheap motorcycles from Asia. The questions included in the checklist were:

a. How many days did each transportation system take to deliver a bushmeat package from the source (e.g. Robanda) to the marketplace (Kowak)?

b. What weights (in $\mathrm{kg}$ ) of sundried bushmeat did each transportation system carry to the marketplace (Kowak) located $200 \mathrm{~km}$ from the source (Robanda)?

c. What was the cost per day incurred by bushmeat vendors when transporting a bag of bushmeat from the source to the marketplace?

Once interviewed, the respondent was asked to identify another candidate involved in the bushmeat business that he/she knew from the village for further interviews. We repeated the same procedure until we were unable to identify any new candidates (we reached the saturation point). All interviews were recorded using an Olympus Digital Voice Recorder (WS-650S). The respondents were alerted that the discussion would be recorded for scientific analysis and not for any other purpose, and that we would delete their voices soon after we had completed the analysis.

\section{Depletion Rate}

The depletion rate is the rate at which each transportation system clears a bushmeat package from the source-to-sink area, which is estimated to be an average of $200 \mathrm{~km}$. The depletion rate, $\mathrm{D}$ is given by: $\mathrm{D}=\mathrm{Mean}$ weight $(\mathrm{kg})$ of bushmeat carried per trip/number of days per trip. 


\section{Statistical Analysis}

Statistical tests were performed using the Statistical Package for the Social Sciences (SPSS, Version 22 for Windows). Descriptive statistics were used to calculate the means and standard errors of the mean. The results were presented as Mean \pm Standard Error. Non-parametric tests were employed to compare the mean time it takes to deliver bushmeat bags, and the mean weights of bags carried by three transportation systems. For all comparisons among test categories, $\mathrm{p}>0.05$ was considered insignificant.

\section{Results}

\subsection{An Overview}

The researchers decided to use information from Robanda and Kowak (pooled data) to estimate the volume of illegal bushmeat, since a good number of informants from the two villages were ready to participate in the current study. Thus, the mean number of days taken by each transportation system was calculated from the village to the market. The majority of bushmeat vendors declined to participate, as only 142 persons accepted among 316 potentially identified bushmeat vendors in the two villages: Robanda and Kowak. Other villages, such as Rwamkoma, Ratia, Tatwe and Osiri, were included in the first place when the project was launched; however, due to the low number of participants (Osiri: $\mathrm{n}=1$; Rwamkoma: $\mathrm{n}=0$; Ratia: $\mathrm{n}=1$ and Tatwe: $\mathrm{n}=0$ ), the information from these villages was not included in the subsequent analysis. Overall, the respondents had been involved in the illegal bushmeat business for $9.2 \pm 0.6$ years $(\mathrm{n}=142)$.

\subsection{Mean Number of Days Spent Delivering Bushmeat Bags to Illegal Markets Using Different Transport Systems}

The respondents from the two villages $(n=142)$ were asked how many days they or the bushmeat vendors known to them used with different means of transport. Overall, the respondents claimed that it took $16.8 \pm 1.0$ days to deliver bushmeat bags to the market, located $200 \mathrm{~km}$ away (Kowak) from Robanda (the source area) when using donkeys, and $6.8 \pm 0.4$ days when using bicycles, while only $2.0 \pm 0.1$ days were required for motorcycles. In this analysis, motorcycles were 8.4 and 3.4 times faster than donkeys and bicycles, respectively. Similarly, bicycles were 2.5 times faster than donkeys. The mean number of days spent by the three different transport systems to deliver bushmeat bags to the market in Kowak differed significantly (Kruskal-Wallis, $\chi^{2}=241.9$, $\mathrm{df}=2, \mathrm{p}<0.05$ ).

\subsection{Mean Weights of Bushmeat Packages Delivered Per Trip by Each Transportation System}

Overall, the mean weights of bushmeat delivered per trip by a donkey, as reported by the interviewed respondents, were $188.4 \pm 4.1 \mathrm{~kg}$ and $109.0 \pm 2.0 \mathrm{~kg}$ when using a bicycle. A motorcycle delivered $185.0 \pm 3.7 \mathrm{~kg}$ of bushmeat per trip. The weights carried by the three transportation systems differed significantly (Kruskal-Wallis, $\chi^{2}=202.6$, $\mathrm{df}=2, \mathrm{p}<0.05$ ). However, donkeys and motorcycles carried similar weights of bushmeat per trip (Mann-Whitney, $\mathrm{U}=9756$, NS), while both donkeys and motorcycles carried heavier loads than bicycles (donkeys vs bicycles: Mann-Whitney, $\mathrm{U}=1696, \mathrm{p}<0.05$ : motorcycles vs bicycles: Mann-Whitney, $\mathrm{U}=1426, \mathrm{p}<0.05$, respectively). Donkeys and motorcycles carried almost 1.7 times heavier loads than bicycles.

\subsection{Depletion Rate}

The mean depletion rate of motorcycles was $92.5 \mathrm{~kg}$ of bushmeat per day, or $3.8 \mathrm{~kg}$ of bushmeat per hour. The depletion rate of bicycles was $16.0 \mathrm{~kg}$ per day or $0.7 \mathrm{~kg}$ per hour, while the rate of depletion by donkeys was only $11.2 \mathrm{~kg}$ per day, which is equivalent to $0.5 \mathrm{~kg}$ per hour. For a male buffalo that weighs $800 \mathrm{~kg}$ (live weight), with a usable meat weight of $300 \mathrm{~kg}$, it would take a motorcycle 3 days, 5 hours, and 45 minutes to deplete the full buffalo. Likewise, for the same carcass, it would take 18 days, 17 hours, and 31 minutes for a bicycle to clear it from the source to the market located $200 \mathrm{~km}$ away, while a donkey would require 26 days, 18 hours, and 50 minutes to clear the carcass from the source to the market, located $200 \mathrm{~km}$ away.

\subsection{Costs Associating with Bushmeat Package Delivery}

The respondents were asked to explain and enumerate the costs they incur when transporting bushmeat bags from the source to the marketplace. Most of the respondents who participated in the current survey claimed that a major cost they considered significant was when game rangers or policemen apprehended the cargo. In such cases, two things were expected to the apprehended cargo. First, the owners of the cargo would run away and leave the cargo with the rangers, who would decide whether to take the cargo using the donkeys, or to unload it and leave the donkeys at the site. Second, they would bribe the rangers or policemen, and if that was successful, they paid the agreed upon amount. Under such scenarios, it is not easy to estimate the total costs. However, in a group of ten people walking with donkeys, they usually set aside approximately USD 200 for what they call 'road clearance fee'. Since most of the respondents did not keep diaries, they were unable to enumerate the costs they incurred to 
maintain their bicycles and motorcycles. Costs that were easy to enumerate were related to the food that the respondents consume on the way to and from the marketplace. They were able to enumerate the amount they spent per day (i.e. breakfast, lunch and dinner). When walking with a donkey, each person spent approximately USD $3.93 \pm 0.22$ per day. Hence, for 16.8 days of a round trip, they would spend USD 66.02 on food. When cycling, the bushmeat vendors spent USD $3.78 \pm 0.23$. Thus, for a round trip, the vendors would spend USD 25.70 buying food Bushmeat vendors spent less on buying food when using a motorcycle to transport a bushmeat bag. The cost for food per day was USD $2.29 \pm 0.01$, which allows for USD 4.58 for a round trip. However, when riding motorcycles, the cost of fuel was imperative. On average, bushmeat vendors spent USD $0.06 \pm 0.002$ per kilometre for fuel. Thus, for $200 \mathrm{~km}$, the motorcycle would use USD 12.0. The total cost the bushmeat vendors incur for food and fuel when using a motorcycle is therefore USD 16.58 .

\section{Discussion}

We derived our analysed information directly from illegal bushmeat hunters or sellers (or those used to be vendors in the past) using the snowballing approach. Hence, we believe that the numbers of days and weights of carcasses delivered to the marketplace were fairly memorized. The actual days and weights would be correct if they would have recorded weights and days in diaries; however, none of them had diaries. When we asked to understand how a motorcycle is able to carry almost $200 \mathrm{~kg}$, without hesitation, one respondent stood up and piled three bags of charcoal, each weighing approximately $70 \mathrm{~kg}$; one on the left side, another on the right side, and a third on the back of the motorcycle, arranged in such a way that each bag supported another. Then, by using rubber ropes, the load was safely secured for the long trip ahead.

Cooperation between researchers and illegal bushmeat hunters/sellers was made possible, especially when the respondents were assured of confidentiality of the information they were giving. The researchers had the advantage of becoming known to villagers for more than 20 years and working in the same areas. Most people, especially those from the closest village to the park's boundaries, did not like to cooperate with researchers. Thus, only $15.8 \%$ of 316 identified illegal bushmeat hunters/sellers agreed to be interviewed through our snowballing survey in the two villages. This was expected due to their sensitive nature and their reliance on the illegal bushmeat business. Our finding supports the results of Nuno, Bunnefeld, Naiman, and Milner-Gulland (2013), which suggest that only $18 \%$ of households interviewed admitted to being involved in illegal bushmeat hunting around the Serengeti. The majority of respondents who agreed to be interviewed were sensitive and suspicious; they were restless, would walk or move around the room, watch outside through the windows or doors, as if we were expecting park rangers or policemen in the house to arrest them. Thus, the reported data might be somewhat inaccurate; however, we believe the major findings are trustful and conclusive.

Of the three transportation systems deployed to deliver bushmeat packages to the organised markets located 200 $\mathrm{km}$ away from the source village, motorcycles were the most efficient system in terms of the number of days taken, load depletion rate, and costs incurred for buying food and fuel. The second most efficient system was bicycles, while the least efficient was donkeys. Although donkeys carried larger bushmeat bags than bicycles, in the overall analysis of depletion rates, it took more than 26 days for the transportation system to clear a single bushmeat bag derived from one adult male buffalo, while the same carcass would be cleared within three days by motorcycles, and within 18 days via bicycle. A motorcycle uses a fuel-powered engine that is air cooled. Thus, it can run from the source area to the organised market (i.e. $200 \mathrm{~km}$ away non-stop), while bicycles are powered by humans who cannot manage to ride uphill with a heavy load effectively; those on bicycles would climb down and push the bicycle slowly to the top of a hill. However, going downhill, the bicycles became as fast as motorcycles. Donkeys, on the other hand, are slow and walked by humans at a constant slow speed, regardless of topography or terrain. Both humans and donkeys need food and water; hence, they have to rest several times a day.

This effective nature of motorcycles in delivering bushmeat packages to organised markets is becoming a serious problem for the conservation of African large- and medium-sized herbivores. In many African countries, motorcycles imported from Asia are licensed to transport people, replacing traditional taxis with four tyres. First, motorcycle businesses are considered to be a new innovation to boost the economy, especially in rural areas where unemployed young men get long-awaited jobs. Many politicians encourage their voters, and some have bought new motorcycles for their supporters or bribed their opponents to vote for them in the organised elections. When motorcycles were first introduced, since they are relatively cheap, a majority of citizens bought them; therefore, the intended business of ferrying people from one place to another became less efficient (almost everyone owns a motorcycle nowadays). Since the business was no longer profitable, the motorcycle owners had to look for alternative businesses to make use of their motorcycles. In large cities with heavy car traffic, motorcycles became involved in organised banditry, attacking banks and bureaus de change; some motorcyclists would grab hand bags from pedestrians, especially women, and run away (personal observation in Dar es Salaam in February 2018, and 
in Arusha in June 2019). In rural areas, motorcycles are mainly used to ferry charcoal from rural zones to towns as an alternative use other than ferrying people to different destiny, or are used to chase wildlife in protected regions, catching animals using ropes and slaughtering them or carrying them alive to the village. Currently, motorcycles are becoming useful in the efficient and effective transportation of illegal bushmeat. As reported by one respondent from Robanda, 'Using a motorcycle is very effective and efficient. In the past, when we started using donkeys, it was very ineffective; we had to stop several times and would send our friends in each village ahead to patrol the road for us. Remember, there were no mobile phones. The patrol men in each village would be paid some pieces of meat or money. Some were not good; you would pay him what he deserved, but he would report you to policemen or game rangers. The rangers or policemen would confiscate the meat if you failed to bribe them to the tune they demanded. After confiscating your meat, the reporter would be paid some more. Another problem with donkeys was the fact that you must offload the package to allow the animal to feed. During night-time, you would get lions or spotted hyenas threatening the donkeys that would drop the load down to run for their lives. In such situations, some member of our group would chase the donkeys to bring them back, while some remained on the ground to take care of the dropped bags of meat. You can now understand why we had to have a big group of people. In addition, donkeys always bray for one or two hours, even at night. The braying was so loud that it would attract policemen or game rangers. With donkeys, you have to know the safe route. Bicycles used to be better than donkeys, but on each trip, you would carry a smaller bag than with donkeys. With a bicycle, you must have enough money to buy food on the way, especially when you are going down to the source village. This is because you are the engine'. Many respondents had similar observations; motorcycles are the most efficient compared to donkeys or bicycles.

\section{Conclusion and Recommendations}

This study concludes that illegal bushmeat hunters who live close to protected areas are more sensitive to issues regarding illegal bushmeat hunting than those located farther away. We also deduced that motorcycles are the most efficient transportation system in terms of a bag's weight, as well as the costs incurred, and the time taken to deliver the bushmeat package to a predetermined market. Finally, as far as cheap motorcycles imported from Asia to Africa are concerned, the illegal bushmeat business is expected thrive to the extent that most herbivore species targeted for bushmeat might go extinct if strict conservation measures are not adhered to.

We recommend the following:

a. Control the use of motorcycles close to protected areas;

b. Wildlife authorities should establish night patrols to arrest illegal bushmeat vendors who use motorcycles;

c. Wildlife authorities should educate local communities, especially motorcycle riders, on conservation issues.

\section{Acknowledgments}

This study was financed through the EU's AfricanBioServices project (Grant \# 641819). We thank village leaders especially those from Kowak and Robanda villages. We also thank our respondents from Kowak and Robanda villages for accepting our request of interviewing them on issues related to illegal bushmeat, which is considered sensitive to majority of illegal bushmeat dealers. We also thank our assistants from the two villages for assisting in nomination of illegal bushmeat dealers.

\section{Conflict of interests}

The authors declare that there is no conflict of interests regarding the publication of this paper.

\section{References}

Apaza, L., Wilkie, D., Byron, E., Huanca, T., Leonard, W., Perez, E., ..., \& Godoy, R. (2002). Meat prices influence the consumption of wildlife by the Tsimane Amerindians of Bolivia. Oryx, 36(4), 382-388. https://doi.org/10.1017/S003060530200073X

Brashares, J. S., Golden, C. D., Weinbaum, K. Z., Barrett, C. B., \& V, O. G. (2011). Economic and geographic drivers of wildlife consumption in rural Africa. Proceedings of the National Academy of Sciences of the United States of America, 108(234), 13931-13936. https://doi.org/10.1073/pnas.1011526108

Campbell, K., Nelson, V., \& Loibooki, M. (2001). Sustainable use of wild land resources: Ecological, Economical and Social interactions. An analysis of illegal hunting of wildlife in Serengeti National Park, Tanzania. Retrieved from Chatham, Kent, UK.:

Cowlishaw, G., \& Dunbar, R. (2000). Primate Conservation Biology. London, UK: University of Chicago Press Ltd. 
Fa, J. E., Juste, J., Burn, R. W., \& Broad, G. (2002). Bushmeat consumption and preferences of two ethnic groups in Bioko Island, West Africa. Human Ecology, 30(3), 397-416. https://doi.org/10.1023/A:1016524703607

Falconer, J. (1990). The major significance of 'minor' forest products: The local use and value of forests in the West African humid forest zone.

Loibooki, M. T., Hofer, H., Campbell, K. L. I., \& Marion, E. L. (2002). Bushmeat hunting by communities adjacent to the Serengeti National Park Tanzania. Environmetal Conservation, 29(3), 391-398. https://doi.org/10.1017/S0376892902000279

Mbete, R. A., Mboko, H. B., Racey, P., Ntsakala, A. M., Nganga, I., Vermeulen, C., ..., \& Leroy, L. P. (2011). Household bushmeat consumption in Brazzaville, the Republic of the Congo. Tropical Conservation Science, 4(2), 187-202. https://doi.org/10.1177/194008291100400207

Mfunda, I. M., \& Røskaft, E. (2010). Bushmeat hunting in Serengeti, Tanzania: An important economic activity to local people. International Journal of Biodiversity and Conservation, 2(9), 263-272.

Nasi, R., Brown, D., Wilkie, D., Bennett, E., Tutin, C., van Tol, G., \& Christophersen, T. (2008). Conservation and use of wildlife-based resources: The bushmeat crisis. CBD Technical Series, 33, 1-50.

Ndibalema, V. G., \& Songorwa, A. N. (2008). Illegal meat hunting in serengeti: Dynamics in consumption and preferences. African Journal of Ecology, 46(3), 311-319. https://doi.org/10.1111/j.1365-2028.2007.00836.X

Nuno, A., Bunnefeld, N., Naiman, L. C., \& Milner-Gulland, E. J. (2013). A Novel Approach to Assessing the Prevalence and Drivers of Illegal Bushmeat Hunting in the Serengeti. Conservation Biology. https://doi.org/10.1111/cobi.12124

Nyahongo, J. W., East, M. L., Mturi, F. A., \& Hofer, H. (2005). Benefits and costs of illegal grazing and hunting in the Serengeti ecosystem. Environmental Conservation, 326-332. https://doi.org/10.1017/S0376892906002566

Nyahongo, J. W., Holmern, T., Kaltenborn, B. P., \& Røskaft, E. (2009). Spatial and temporal variation in meat and fish consumption among people in the western Serengeti, Tanzania: The importance of migratory herbivores. Oryx, 43(2), 258-266. https://doi.org/10.1017/S0030605307991127

Rentsch, D., \& Damon, A. (2013). Prices, poaching, and protein alternatives: An analysis of bushmeat consumption around Serengeti National Park, Tanzania. Ecological Economics, 91, 1-9. https://doi.org/10.1016/j.ecolecon.2013.03.021

UNEP. (2008). Serengeti National Park, Tanzania. In C. J. Cleveland (Ed.), Encyclopedia of Earth. Washington DC, USA: Environmental Information Coalition, National Council for Science and the Environment.

Wilkie, D. S., \& Carpenter, J. F. (1999). Bushmeat hunting in the Congo Basin: An assessment of impacts and options for mitigation. Biodiversity and Conservation, 8(7), $927-955$. https://doi.org/10.1023/A:1008877309871

Wilkie, D. S., \& Godoy, R. A. (2001). Income and price elasticities of bushmeat demand in lowland Amerindian societies. Conservation Biology, 15(3), 761-769. https://doi.org/10.1046/j.1523-1739.2001.015003761.x

Wilkie, D., Schenck, M., Effa, E. N., Starkey, M., Abernethy, K., Telfer, P., ..., \& Treves, A. (2006). Why people eat bushmeat: Results from two-choice, taste tests in Gabon, Central Africa. Human Ecology, 34(3), 433-445. https://doi.org/10.1007/s10745-006-9025-1

\section{Copyrights}

Copyright for this article is retained by the author(s), with first publication rights granted to the journal.

This is an open-access article distributed under the terms and conditions of the Creative Commons Attribution license (http://creativecommons.org/licenses/by/4.0/). 